\title{
Getting to Grips with Idioms: Greek Learners vis-à-vis English Idioms
}

\author{
Despoina Panou ${ }^{1}$ \\ ${ }^{1}$ School of Education, University of Leicester, 21 University Road, Leicester, LE1 7RF, U.K. \\ Correspondence: Despoina Panou, 4 Gioldasi street, Athens 117 44, Greece. Tel: 30-697-810-8278. E-mail: \\ despanou@yahoo.gr
}

Received: August 1, 2013 Accepted: August 25, 2013 Online Published: August 28, 2013

doi:10.5430/ijelt.v1n1p11 URL: http://dx.doi.org/10.5430/ijelt.v1n1p11

\begin{abstract}
The present paper aims at examining Greek learners' comprehension and production errors in L2 idiom learning. To this end, four exercises - two focusing on receptive skills and two on productive ones - were distributed to 50 Greek native speakers of advanced English Proficiency in order to assess which idiom-type(s) and exercises cause the biggest problem to Greek learners. It was shown that L2 learners made more errors in idiom-production exercises than in comprehension-based ones and that the biggest error percentage was found in idioms with both structural and semantic dissimilarity to L1 idioms. These findings suggest that Greek learners of English tend to understand the meaning of L2 idiomatic expressions through the use of contextual information and conceptual knowledge but are unable to use them in their own language production, thus making structural, grammatical and contextual mistakes.
\end{abstract}

Keywords: idiom comprehension, idiom production, error treatment, Greek learners of English

\section{Introduction}

Idioms seem to constitute a highly problematic area for both teachers and learners (see, for example, Wray, 2000; Wood, 2002; Schmitt, 2004, Moon, 1998; Liu, 2008). In particular, this general reticence towards idiom teaching and learning is reinforced by the very complex nature of idioms and by the fact that each idiom has its own syntactic, semantic and pragmatic idiosyncrasies. In outlining the difficulties involved in learning idioms, Irujo (1986) mentions their non-literalness and learners' limited exposure to them. She also acknowledges the fact that even if learners do master the meanings of some English idioms, they have a considerable difficulty in using them accurately because they do not fully comprehend their grammatical constraints and/or their situational appropriateness. In addition to that, many second-language teaching materials do not help them since they either ignore idioms entirely or consider idiomatic language of peripheral importance. Evidence of this belief are "the countless separate little books of idioms for various foreign languages often published as a sort of optional adjunct to grammars and dictionaries" (Lennon, 1998:5). Given the difficulties that idioms pose to L2 learners, the present study attempts to shed some light on L2 idiom comprehension and production issues by answering two interrelated questions: (a) which type of idiom exercises - comprehension or production ones - create the biggest problems for Greek learners of English and (b) which idiom-type(s) cause the biggest error percentage.

\section{Teaching idioms: Some Critical Reflections}

Given the enormous difficulty involved in L2 idiom comprehension and production, it is useful to see what instructional methods have been proposed by researchers and teachers in order to help learners get to grips with these expressions. In particular, Irujo (1986:238) sets out five criteria for deciding which idioms to teach, namely, their frequency of use, their degree of transparency, their appropriateness, their simplicity of form and vocabulary and lastly, their similarity to first-language idioms. Moreover, Pinnavaia (2002:55-57) argues that in order for learners to cope with this complex phenomenon, they need to have control of idioms' meaning, structure and textual function. As regards meaning control, an awareness of the cultural and historical origin of idioms as well as a contrastive analysis with the learners' mother-tongue idioms can reinforce an analytical meaning-deciphering approach. With regard to structure control, it should be made clear to learners that not all idioms are inflexible and that there are various degrees and types (e.g. lexical, grammatical) of idiomatic variability. Lastly, to gain functional control of idioms, learners should be able to "distinguish between formal and informal, polite and derogatory, general English or special English idiomatic expressions so that they can fully understand the text in which they appear" (2002:58).

This of course, brings us to the next question, which is no other than what we can do to teach idioms effectively. 
Irujo (1986:240-241) stresses that we should focus on teaching both idiom comprehension and production. She proposes fill-in exercises, picture drawing of both literal and idiomatic meanings of an idiom, story writing, dialogues, idiom charades, add-on stories, short plays containing idioms, role-play, etc. Furthermore, acknowledging the metaphoric nature of idioms, Lennon (1998:7) argues that learners can unearth the underlying metaphors found in idiomatic language and thus make sense of these semantically opaque expressions. In addition to that, by designing a CALL package for Chinese idiom learning, Luk and $\mathrm{Ng}$ (1998:2) have shown that computers can assist students in learning Chinese idioms more effectively.

Richards (1996) has proposed a two-way route to idiom instruction, namely, the proactive and the retroactive way. As the word suggests, the proactive way assumes a conscious effort from the part of the teachers to teach students and help them use as many idioms as possible. On the other hand, the retroactive approach implies a more unconscious approach to idiom instruction and rests itself in helping students figure out the meaning of an idiom in case they encounter one. Richards (1996) is careful to note that the first approach may result into 'idiomatosis', which means excessive and often inappropriate use of idioms, but as Liu (2008:136-137) suggests the overuse or inappropriate use of specific linguistic constructions is part of the language learning process. Hence, it is not a good enough reason to exclude active idiom teaching altogether.

In fact, Liu (2008) in his monograph Idioms: Description, Comprehension, Acquisition and Pedagogy argues for the use of both macro- and micro-strategies for effective idiom teaching. In his idiom pedagogy plan there are three stages, namely, noticing and identifying idioms, understanding them and using them. According to him (2008:139) the identification of idioms can be achieved through a variety of activities such as looking an idiom in a dictionary, highlighting idiomatic expressions in a text and conducting corpus searches for idioms. With respect to the second stage, some meaning-guessing strategies involve the use of pragmatic and conceptual knowledge, the use of context and knowledge of L1 idioms, dramatization and picture drawing of idioms (2008:143-148). Lastly, some idiom production activities include the making of sentences or paragraphs using idioms, the completion of a story or paragraph with an idiom, telling stories based on pictures by using idioms and role-playing dialogues which contain idioms that students have created themselves (2008:156-159). Lastly, in examining the strategies fourteen college instructors use to teach idioms, Liu (2000) has argued that the three most dominant strategies for explaining idioms are: definition, elaboration and paraphrasing (cited in Liu, 2008:162). In the first strategy, the instructor provides the students with the meaning of the idiom whereas in the second one it explains its meaning by providing further information and examples that will facilitate students' understanding of these semantically opaque expressions. Finally, the paraphrasing strategy involves the use of a different expression to transfer the same meaning. There are no hard and fast rules as to what or how many strategies teachers should use. The language level of students, their age, their learning patterns as well as the degree of idiom difficulty obviously have a say in what kind of technique will be adopted by the teacher. The one thing that is sure is that teachers should be flexible and ready to adapt to their students' needs by employing various strategies that will help them reach their target.

To recapitulate, idioms are not meant to be dealt with in a short of "out of sight out of mind" fashion. Students should be encouraged to become acquainted with them and it is the teachers' responsibility to make them an integral part of vocabulary learning by presenting them in non-threatening naturalistic situations.

\section{Research Methodology}

In order to examine Greek learners' comprehension and production errors in L2 idiom learning, four exercises - two focusing on receptive skills and the other two on productive ones - were distributed to 50 Greek native speakers of advanced English Proficiency. The student sample consisted of 50 (35 female and 15 male) Greek native speakers of advanced English proficiency whose age varied from 15 to 27. In particular, all subjects were students in an English Language School in Athens. Subjects' L2 proficiency, and their experience with idioms were assessed through a brief preliminary questionnaire and a self-assessment scale (the latter been adopted from Bachman and Palmer 1989; see Panou, 2006:85-86), which the subjects filled out before they were given the four exercises.

To explain, all subjects were volunteers and rated themselves as advanced speakers of English. In more detail, they all reported to have at least seven years of experience with the English language, scoring a mean average of 10.46 years, but only five subjects reported to have spent an average of 6 months in an L2 environment. As far as their grammatical competence is concerned, fifteen subjects stated that they almost never make grammatical mistakes, ten subjects declared that they only make a few and only five out of fifty reported to make many kinds of grammatical mistakes. With respect to their vocabulary competence, eighteen students reported that they often feel that they do not know the meaning of a word whereas only twelve stated to seldom experience such feeling.

As far as the subjects' experience with idioms is concerned, it was reported that the majority of subjects (45) has 
been exposed to idiomatic expressions through the use of various exercises employed by their teachers and only five subjects claimed to have received no idiom pedagogy. Furthermore, they scored a mean of 4.33 in an idiom-importance assessment 5-point scale and all subjects with the exemption of three stressed the importance of idiom dictionaries even though they admitted that they rarely read specialized dictionaries. Furthermore, a significant number of subjects (39) stressed that they sometimes discuss idioms with their instructor and rarely with their classmates but wished they had more exposure to idiomatic constructions in real-life situations. Lastly, they all stated that they want idioms to be part of the foreign language curriculum and forty-five out of fifty reported to often feel uncomfortable around people who use idioms.

With respect to the four exercises constructed, the first two focused on receptive skills and the other two concentrated on productive ones. To explain, in the first exercise, students were asked to fill in the gaps by choosing from the idiomatic expressions given, in the second one, students were required to fill in part of the idiom by using the words provided whereas the third one was again a gap-filling exercise but this time no idiomatic expressions were provided but only the headwords of the missing idioms and the number of gaps. Lastly, the fourth exercise was based on a story-completion task in which no list of idioms was provided but instead students were given the headwords of the idiomatic expressions that they were supposed to find as well as the number of gaps that will help them figure out the number of words the missing idiom consists of (Appendix A).

Following O'Keeffe, McCarthy, and Carter (2007), I decided to select forty idioms that contained certain basic everyday words such as body parts. With respect to idiom typology, I adopted Yoshikawa's idiom taxonomy (2008), which is a rather recent one, and has as its primary criterion in classifying idioms, the degree of structural and semantic similarity an L1 idiomatic construction exhibits in relation to an L2 idiomatic construction. According to Saberian and Fotovatnia (2011) structural similarity between an L1 and an L2 idiom is assumed to exist "if the major content words could be literally translated to L1" and semantic similarity is achieved only when both the L1 and L2 idiom "share the same central concept, and could be used in the same contexts" (2011:1232). In more detail, Yoshikawa (2008) classifies idioms into five different types:

1. Type A idioms, are idioms which have structural and semantic similarity to L1 idioms.

2. Type B idioms are idioms which have partly structural and semantic similarity to L1 idioms.

3. Type $\mathrm{C} 1$ idioms are idioms which have structural similarity to $\mathrm{L} 1$ idioms but semantic dissimilarity.

4. Type $\mathrm{C} 2$ idioms are idioms which do not have any structural or semantic similarity to L1 idioms.

5. Type D idioms (this idiom-type was added by Saberian, 2011) are idioms which have semantic similarity to L1 idioms but exhibit structural dissimilarity.

Implementing this idiom classification to the 40 idioms containing body parts the following taxonomy occurs:

Type A idioms: be all ears, go in one ear and out the other, bite one's tongue, have one foot at the grave, stand on your own feet, open someone's eyes, an eye for an eye, put words into someone's mouth.

Type B idioms: risk your neck, work your guts out, make your hair curl, a hair's breath, not a hair out of place, tear your hair out, in your hair, bound hand and foot.

Type C1 idioms: to have fleas in one's ears, put your foot down, in the palm of your hand, with one hand tied behind your back, your heart is in the right place, on your hands, a head of steam, keep your head down.

Type C2 idioms: up in arms, play it by ear, wet behind the ears, have green fingers, come to a head, wear your heart on your sleeve, break a leg, cut your teeth.

Type D idioms: have eyes in the back of your head, on someone's lips, someone's lips are sealed, button your lip, bear something in mind, slip your mind, make your mouth water, froth at the mouth.

To explain, Type A idioms include idiomatic expressions almost identical at the syntactic, semantic and pragmatic level with their Greek idiomatic counterparts as is evident:

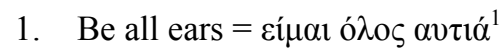

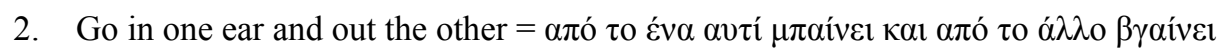

3. Bite one's tongue $=\delta \alpha \gamma \kappa \omega ́ v \omega \tau \eta \gamma \lambda \omega ́ \sigma \sigma \alpha \mu$ ov

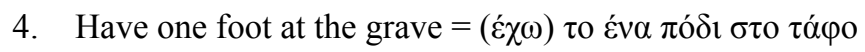

5. Stand on your own feet $=\sigma \tau \varepsilon \dot{\kappa} \kappa \mu_{\alpha \iota} \sigma \tau \alpha \pi$ ó $\delta 1 \alpha \mu$ ov 


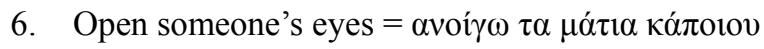

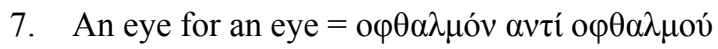

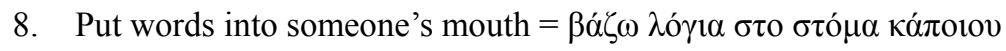

In Type B idioms, there is partial structural and semantic similarity to L1 idioms as can be seen below:

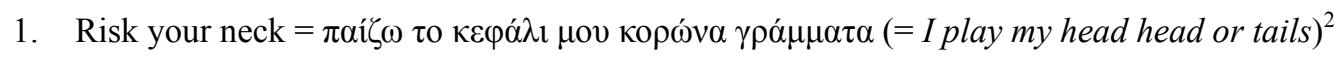

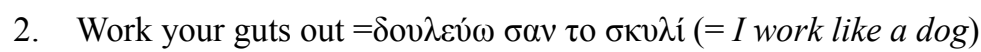

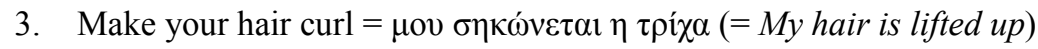

4. A hair's breath $=\pi \alpha \rho \alpha$ $\tau \rho i ́ x \alpha(=$ next to a hair $)$

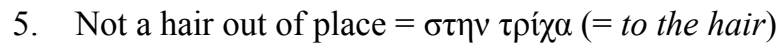

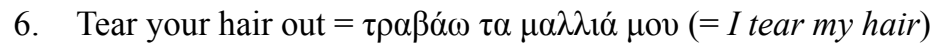

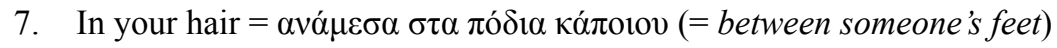

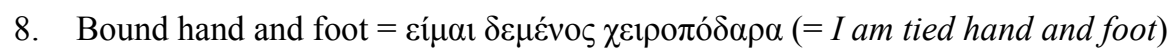

In Type $\mathrm{C} 1$, there are idioms with structural similarity but semantic dissimilarity to L1 idioms. Idioms belonging to this type could be classified as false friends since as Dobrovol'skij (2005) argues "they resemble each other on the level of mental images and lexical constituents, i.e. on the level of inner form, whereas they display significant differences on the semantic level" (2005:109). It should be mentioned that Nicholls (2002:1) has pointed out that difference in meaning is varied since we can have total or partial semantic dissimilarity. Al-Wahy (2009:106) observes that apart from the fact that an idiom can have both a literal and an idiomatic meaning, it can also have more than one idiomatic meaning as is with examples 2,3,4,6,7 and 8. According to Dobrovol'skij (2005:69) these idioms exhibit the property of "assymetrical polysemy". In his words (2005:69) this happens when "a given L1idiom has more than one meaning, whereas the corresponding L2-idiom only has one meaning". There are also cases of false friends which function as "deceptive cognates" (Ferguson, 1994:x) and in this case there are English idioms which have similar form and structure with the Greek ones, but completely different meaning as is the case with examples 1 and 5:

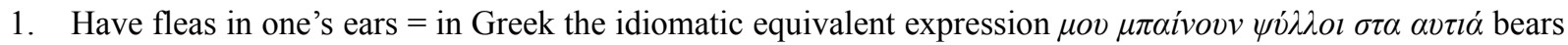
the meaning of becoming mistrustful whereas in English the idiom signifies "a sharp reproof or rebuke" (Dobrovol'skiji, 2005:110)

2. Put your foot down = in English it has two meanings; firstly, you use your authority in order to stop something from happening and secondly, you start to drive as fast as you can. In Greek, only the first meaning is valid $\left(=\pi \alpha \tau \dot{\alpha} \omega \pi \delta^{\delta} \delta\right)$.

3. In the palm of your hand = in English, it can either mean that people are giving you their full attention and are responding enthusiastically to everything you say or do or that you have complete control over someone and they will do whatever you want them to do. In Greek, only the second meaning holds (= $\varepsilon^{\prime} \chi \omega \kappa \dot{\alpha} \pi$ olov $\sigma \tau \alpha$

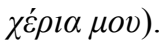

4. With one hand tied behind your back = in English, it has two meanings, namely, you can do something very easily and secondly, you have a disadvantage which makes it difficult for you to succeed. When Greeks use this idiom they normally refer to its second meaning $\left(=\mu \varepsilon \delta \varepsilon \mu \varepsilon \dot{\varepsilon} v \alpha \alpha \chi^{z} \hat{\varepsilon} \rho l \alpha\right)$.

5. Your heart is in the right place $=$ in Greek the idiomatic equivalent expression is $\eta \kappa \alpha \rho \delta i \alpha \dot{\alpha} \mu o v \pi \eta \dot{\eta} \gamma \varepsilon \sigma \tau \eta \theta \dot{\varepsilon} \sigma \eta$ $\tau \eta \varsigma$ and it means that you stop being anxious about something whereas when someone uses this idiom in English they mean that someone is generous, kind and considerate, although they may lack other qualities which you consider to be important.

6. On your hands = in English, this idiom is used to indicate that you are responsible for caring or dealing with someone. It also means that you have to deal with a problem or an unpleasant task. In Greek, this idiom is

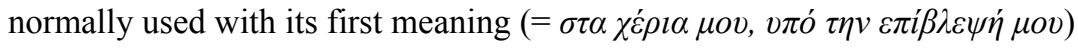

7. A head of steam = in English, it refers to someone who gradually becomes more and more angry, anxious or emotional about something, until they can no longer hide their feelings. In addition to that, if someone gets a head of steam for a plan or cause, they gain a lot of support for it. The Greek equivalent idiomatic expression

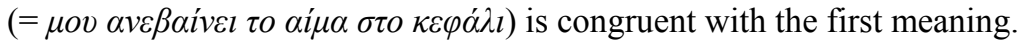


8. Keep your head down = the English idiom has a double meaning; firstly, in a difficult or dangerous situation, you try to avoid trouble or involvement by behaving in a quiet way so that people will not notice you. Secondly, if you keep your head down, you continue to concentrate and work hard at something. The Greek

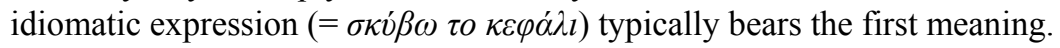

On the other hand, Type $\mathrm{C} 2$ idioms exhibit both structural and semantic dissimilarity as is shown below:

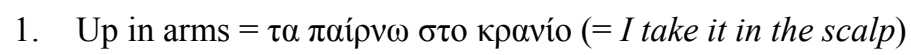

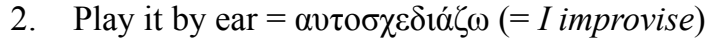

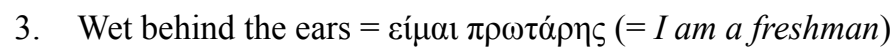

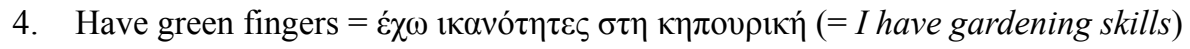

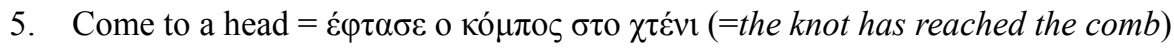

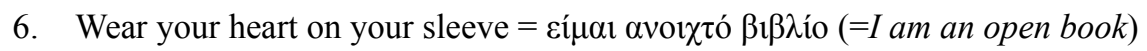

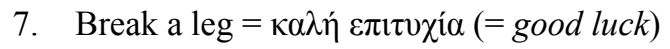

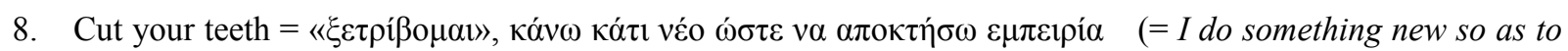
gain experience)

Lastly, Type D idioms have semantic similarity to L1 idioms but exhibit structural dissimilarity as can be seen below:

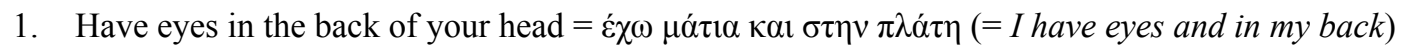

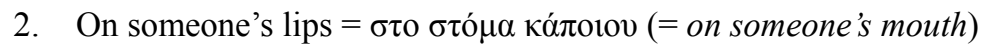

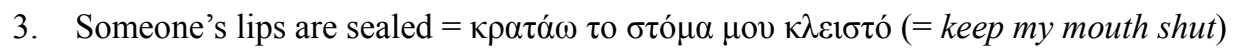

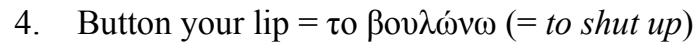

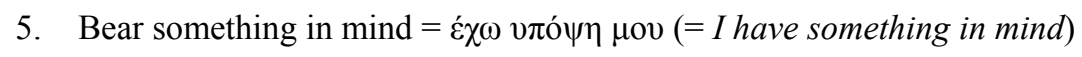

6. Slip your mind $=\mu$ ov $\delta 1 \alpha \varphi \varepsilon v ́ \gamma \varepsilon 1$ (= it slips my mind)

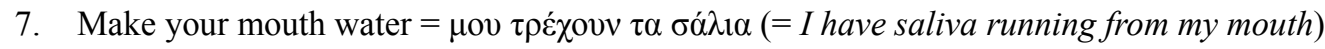

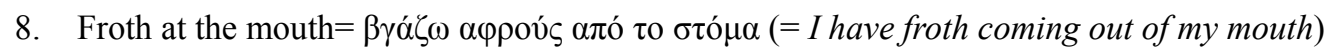

So each exercise comprised of ten idioms, two from each idiom-type. In particular, the first two idioms of the above five idiom categories were used in the first exercise, the second two idioms from each idiom-type were used in the second exercise etc. Thus, having described the research methodology that will be employed for the analysis of the data, I will now proceed to critically discuss Greek learners' L2 idiom comprehension and production patterns.

\section{Findings}

The aim of the present study was to look at which idiom-type(s) and exercises caused the biggest problem to Greek learners of English regarding L2 idiom comprehension and production. Firstly, with respect to the four exercises, the following error percentages were observed:

Table 1. Error percentages according to exercise

\begin{tabular}{ll}
\hline Exercise 1 & $31 \%$ \\
\hline Exercise 2 & $23 \%$ \\
\hline Exercise 3 & $39 \%$ \\
\hline Exercise 4 & $37 \%$ \\
\hline
\end{tabular}

As shown in Table 1, the biggest error percentage was found in exercise 3 which is based on productive skills and invites students to fill in the gaps with the correct idiom without giving them the choice of deciding among possible idioms. The second biggest error percentage was noted in the story-completion task which again touches on L2 idiom production. On the other hand, the lowest error percentage was observed in the second exercise in which students were asked to complete part of the idiom. Lastly, exercise 1, in which students were asked to choose the correct idiom drawing from context and encyclopedic knowledge, exhibited the second lowest error percentage. This information is best depicted in Figure 1: 


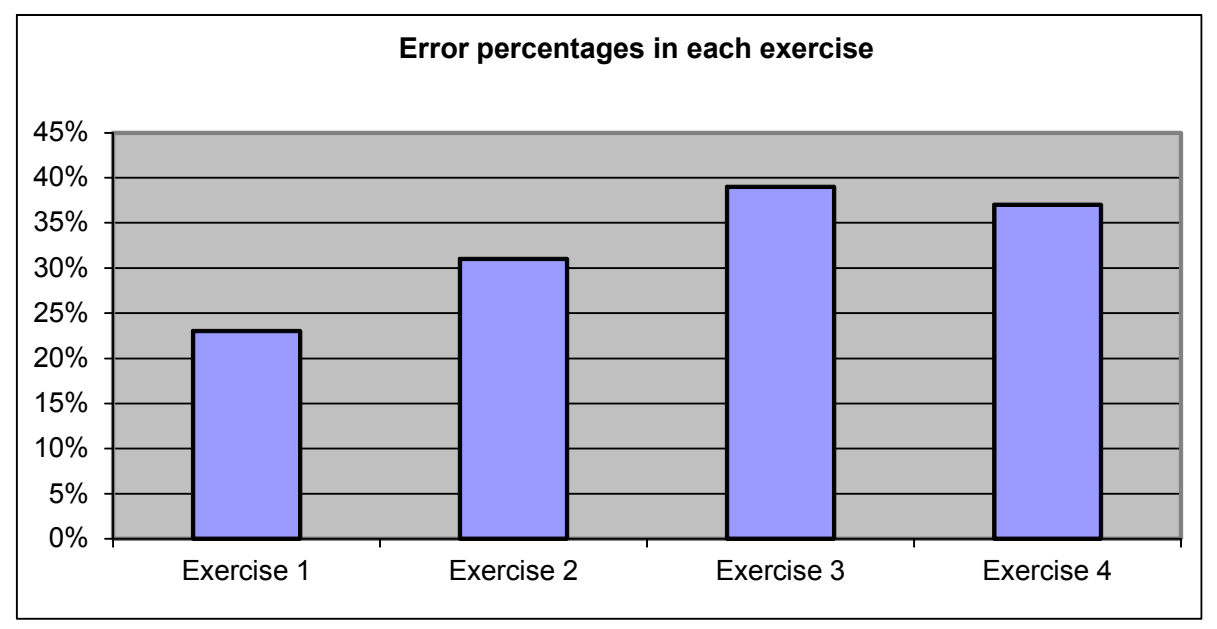

Figure 1. Error percentages in each exercise

On closer inspection of Figure 1, a tentative conclusion that might be drawn is that Greek learners of English made more errors on idiom-production exercises than in comprehension-based ones.

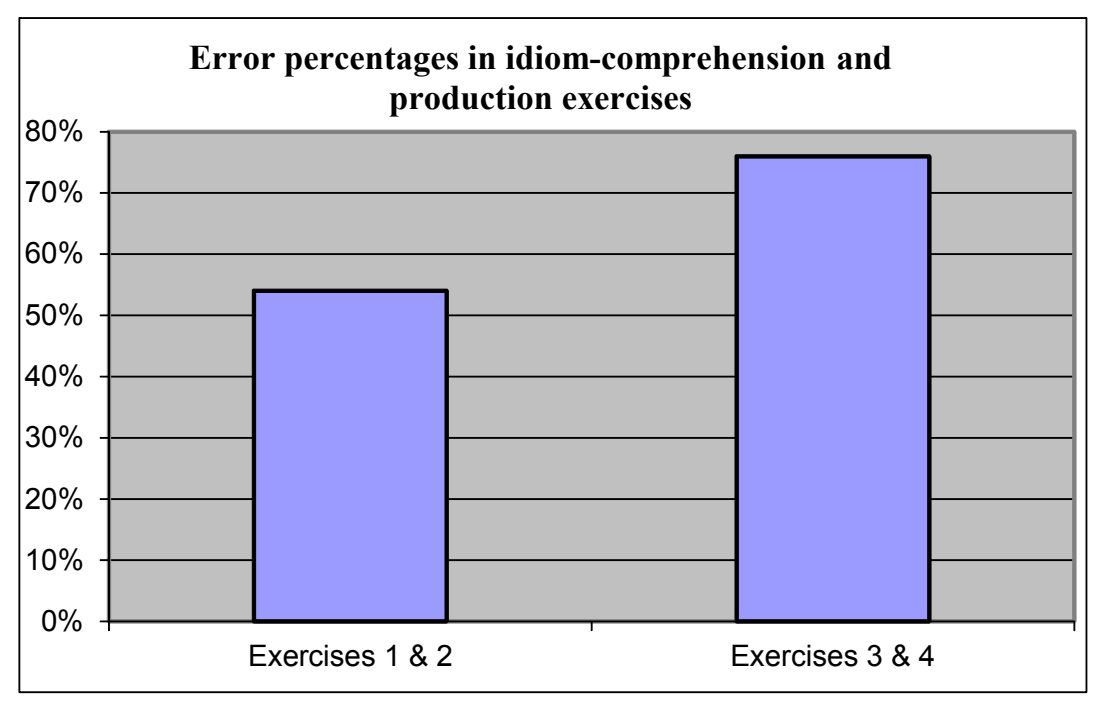

Figure 2. Error percentages in idiom-comprehension and production exercises

Figure 2 illustrates that Greek learners of English made more errors on idiom-production exercises, that is exercises 3 and 4, than in comprehension-based ones, that is, exercises 1 and 2. In Table 2, the error percentages are shown more analytically:

Table 2. Error percentages according to exercise-type

\begin{tabular}{ll}
\hline Exercises $1 \& 2$ & $54 \%$ \\
Exercises $3 \& 4$ & $76 \%$ \\
\hline
\end{tabular}

As shown in Table 2, the error percentages are higher in production-based idiom exercises $(76 \%)$ than in comprehension ones (54\%). This outcome was expected since many L2 learners understand idiomatic expressions 
when they encounter them but are not able to use them accurately in language production. It may be the case that even if they acquire the meaning of a given idiom, they do not have the chance to use it because of its low frequency of use. Hence, idioms may remain in the receptive idiom repertoire instead of being actively used.

As far as idiom typology is concerned, the error percentages according to idiom-type are shown in Figure 3:

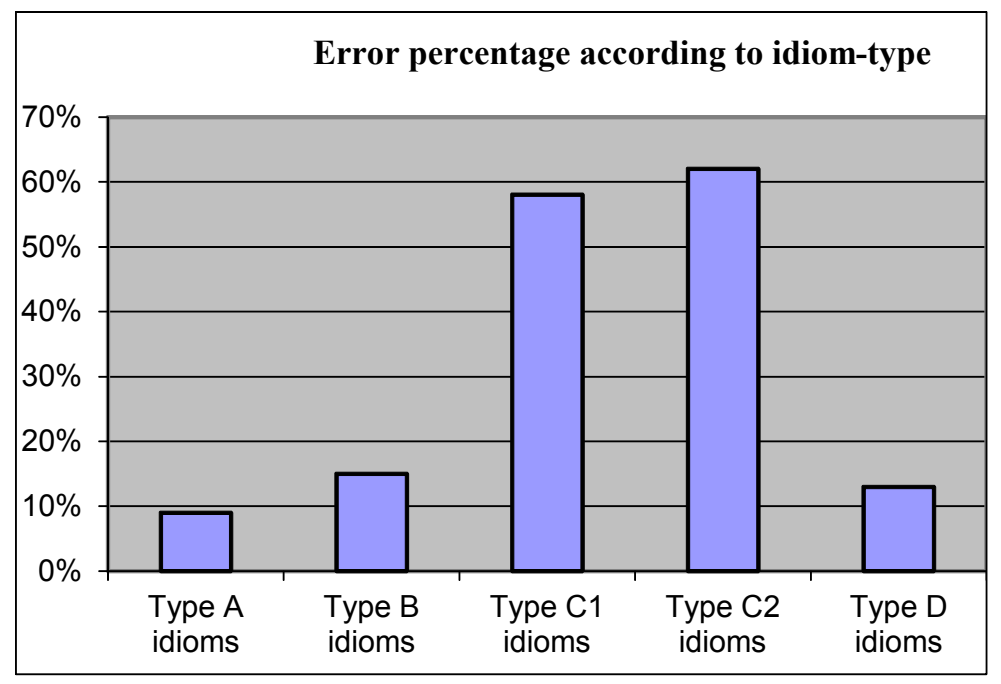

Figure 3. Error percentage according to idiom-type

As is evident in Figure 3, the biggest error percentage is found in Type C2 idioms, that is, idioms with both structural and semantic dissimilarity to L1 idioms.

The percentage errors in the remaining idiom-types are depicted in Table 3:

Table 3. Error percentages according to idiom-type

\begin{tabular}{lc}
\hline Type A idioms & $9 \%$ \\
\hline Type B idioms & $15 \%$ \\
\hline Type C1 idioms & $58 \%$ \\
\hline Type C2 idioms & $62 \%$ \\
\hline Type D idioms & $13 \%$ \\
\hline
\end{tabular}

As shown in Table 3, type $\mathrm{C} 1$ idioms, that is, false friends idioms have the second biggest error percentage (58\%) while idioms with partial structural and semantic similarity belonging to Type B have a $15 \%$. Then Type D idioms follow with a 13\% and lastly, Type A idioms which exhibit both structural and semantic similarity with the English idioms have the lowest error percentage, namely, $9 \%$.

\section{Discussion of the Findings}

The present study sheds light on two important aspects of L2 idiom acquisition. Firstly, foreign language students are far better at deciphering an idiom's meaning resting primarily on contextual information as well as pragmatic and conceptual knowledge than learning to use them in their own language production. The story-completion exercise had a lower error-percentage than the third exercise and this may be partly explained by the fact that more contextual information was provided in the story than in the isolated sentences of exercise 3. The importance of contextualization in both lexical and idiom learning has been stressed by Liu (2008:132) who argues that through the use of contextualized examples of idioms, students can better understand not only their meaning but their potential uses and thus be able to effectively employ them in their own language production. Correct L2 idiom production does not only entail accurate wording and structure but also realization of an idiom's register, connotation and context of use. Students make different kind of errors in their effort to correctly produce an idiom and teachers need to use a variety of strategies in order to bring English idioms home to Greek learners of English. The best way for 
teachers to draw students' attention is to engage them in creative idiom learning through the use of appropriate activities that will reinforce their understanding of idioms and will encourage their use.

Secondly, another important finding of this research is that the biggest error percentage was found in idioms with both structural and semantic dissimilarity to L1 idioms. Consequently, special emphasis should be made to the way these idioms are presented and taught to foreign language learners. Both Cooper (1999) and Irujo (1986) have suggested that idioms that are similar or even identical to L1 idioms should be the first to be presented to students for the simple reason that they pose little difficulty for L2 learners to comprehend. Through this identification and comparison of L1 and L2 idioms, the comparison/contrast process is facilitated because students get to realize the similarities and differences between idioms of different languages. Furthermore, the use of contextual information to decipher an idiom's meaning is a very effective idiom-learning technique. In fact, the use of pragmatic and conceptual knowledge may prove particularly fruitful when dealing with figurative idioms (Liu, 2008:144). Again, the parameters of usefulness and frequency of an idiom come into play because what is useful for a particular group of learners may not be useful for another group. As a general rule, high-frequency idioms should be taught before low-frequency idioms (Liu, 2008:109). On these grounds, it could be argued that students should learn the idioms they need most in terms of their learning goals, thus being encouraged to use them creatively.

\section{Conclusion}

In this paper an attempt was made to examine Greek learners' comprehension and production errors in L2 idiom learning. The results obtained indicate that Greek learners of English are better at idiom-comprehension exercises than production ones. More importantly, the argument was put forward that a criterion of paramount importance in L2 idiom instruction is the idiom's level of similarity to its idiomatic counterpart in the learners' L1 since it was shown that idioms with both structural and semantic dissimilarity to L1 idioms have the biggest error percentage. It is concluded that error treatment and assessment are of paramount importance in idiom instruction and that teachers should employ a variety of activities to deal with different idioms and different learners.

\section{References}

Al-Wahy, A. S. (2009). Idiomatic false friends and Modern Standard Arabic. Babel, 55(2), 101-123. http://dx.doi.org/10.1075/babel.55.2.01wah

Bachman, L., \& Palmer, A. (1989). The construct validation of self-ratings of communicative language ability. Language Testing, 6(1), 14-29.

Betsis, A. (ed.) (2011). Betsis English Idioms in Greek: Collins COBUILD Dictionary. Piraeus: Andrew Betsis ELT Publications.

Cooper, T. C. (1999). Process of idioms by L2 learners of English. TESOL Quarterly, 33, 233-262.

Dobrovol'skij, D. (2005). False friends and paronyms. In D. Dobrovol'skij, \& E. Piirainen (Eds.), Figurative Language: Cross-cultural and Cross-linguistic Perspectives (pp. 107-120). Amsterdam: Elsevier.

Ferguson, R. (1994). Italian False Friends. Toronto: University of Toronto.

Irujo, S. (1986). Don't put your leg in your mouth: Transfer in the acquisition of idioms in a second language. TESOL Quarterly, 20(2), 281-304. Retrieved May 22, 2013, from http://www.jstor.org/stable/3586545

Lennon, P. (1998). Approaches to the teaching of idiomatic language. IRAL, 36(1), 1-11. http://dx.doi.org/10.1515/iral.1998.36.1.11

Liu, D. (2000). Idioms in the instructional language. Paper presented at the $34^{\text {th }}$ TESOL Annual Convention, Vancouver, Canada.

Liu, D. (2008). Idioms. Description, Comprehension, Acquisition, and Pedagogy. London and New York: Routledge.

Luk, R. W. P., \& Ng, A. B. Y. (1998). Computer-assisted learning of Chinese idioms. Journal of Computer Assisted Learning, 14, 2-18. http://dx.doi.org/ 10.1046/j.1365-2729.1998.1410002.x

Moon, R. (1998). Fixed Expressions and Idioms in English: A Corpus-Based Approach. Oxford: Clarendon Press.

Nicholls, D. (2002). Friend or foe? False friends and the language learner. MED Magazine. Issue 3. Retrieved May 11, 2013, from http://www.macmillandictionary.com/med-magazine/December2002/03-languageinterference -false-friends.htm

O'Keeffe, A., McCarthy, M. J., \& Carter, R.A. (2007). From Corpus to Classroom: Language Use and Language Teaching. Cambridge: Cambridge University Press. 
Panou, D. (2006). L2 Idiomatic Comprehension: Do Idioms Reveal Beans or Spill Secrets? Unpublished M.A. dissertation. Surrey: University of Surrey.

Pinnavaia, L. (2002). The grammaticalization of English idioms: A hypothesis for teaching purposes. Mots Palabras Words, 1, 53-60. Retrieved June 1, 2013, from http://www.ledonline.it/mpw/allegati/mpw0102pinnavaia.pdf

Richards, J. C. (1996). Idiomatically speaking. Zielsprache Englisch, 26, 32-33.

Saberian, N. (2011). The Effect of Idiom Type and Individual Differences on Idiom Comprehension and Strategy Use of EFL Students. Unpublished MA thesis. Najafabad: Islamic Azad University.

Saberian, N., \& Fotovatnia, Z. (2011). Idiom taxonomies and idiom comprehension: Implications for English teachers. Theory and Practice in Language Studies, 1(9), 1231-1235. http://dx.doi.org/10.4304/tpls.1.9.1231-1235

Schmitt, N. (Ed.) (2004). Formulaic Sequences. Amsterdam: John Benjamins.

Sinclair, J. McH., \& Moon, R. (eds.) (2002). Collins COBUILD Dictionary of Idioms (2nd ed.). Glasgow: Harper Collins Publishers.

Wood, D. (2002). Formulaic language in acquisition and production: implications for teaching. TESL Canada Journal, 20, 1-15. Retrieved July 21, 2013, from http://teslcanadajournal.ca/index.php/tesl/article/viewFile/935/754

Wray A. (2000). Formulaic sequences in second language teaching: principle and practice. Applied Linguistics, 21(4), 463-489. http://dx.doi.org/101093/applin/21.4.463

Yoshikawa, H. (2008). International intelligibility in world Englishes: focusing on idiomatic expressions. International Communication Studies, 17(4), 219-226. Retrieved July 25, 2013, from http://www.uri.edu/iaics/content/2008v17n4/16\%20Hiroshi\%20Yoshikawa.pdf

\section{Appendix A}

\section{Exercise 1}

1. Read the following sentences and fill in the blanks with one of the idioms below:

be all ears, go in one ear and out the other, risk your neck, work your guts out, a flea in one's ears, put your foot down, up in arms, play it by ear, have eyes in the back of your head, on someone's lips

1. Listen! I've got some terrible news. Come on, tell me. I

2. The question most Greeks' was not whether there would be bankruptcy but when this would happen.

3. I've said it so many times but he can't get it. My words

4. Our two-year old daughter is at the stage where you need

5. I can't really tell you what will happen next. I

6. You are not going to for him. He is not worth it.

7. I had to in order to complete this project on time.

8. Many Greeks are with the new taxes imposed.

9. The clerk was given for not serving the customer.

10. Richard is such a fast driver. He always sticks in the fast lane and

\section{Exercise 2}

2. Use the words below to complete the following idiomatic phrases:

bite, grave, hair's, curl, palm, back, ears, fingers, lips, button 
1. A quick look at the audience shows that Federer has got them in the of his hands.

2. It's best to your tongue when you do not know anything about the topic being discussed.

3. They've got such a lovely garden. Her husband has green

4. My niece got so sick and she felt as if she had one foot in the

5. I do not think that George will cope with the demands of his new job. He is still wet behind the

6. The teacher reprimanded the student and told him to his lip.

7. I will tell you a story that will make your hair

8. Divorce is only a breath way.

9. This program is so easy to operate that you can do it with one hand tied behind your

10. I have sworn not to reveal her secret. My are sealed.

\section{Exercise 3}

3. Read the following sentences and fill in the blanks with the appropriate idiom that contains the following body parts:

feet, eyes, hair, mind, head, hand, heart

1. Many people think they can't do it alone and do not end unhappy relationships. They simply can't

2. It wasn't until her mother came to her house and as to what her husband was doing behind her back.

3. Your appearance is always very tidy. I've never seen you

4. My son's irresponsible attitude and inefficiency makes me

5. Anna can become really annoying sometimes but her

6. I have yet another school problem

7. Matters when the Minister of Education threatened to resign.

8. It is so difficult to know what he is feeling because he simply doesn't

9. There are some general rules you should when writing a dissertation.

10. It must have that you have an appointment with the dentist tomorrow.

\section{Exercise 4}

4. Complete the story with the appropriate idiom that contains the following body parts:

leg, teeth, head, hair, mouth, eye, hand, foot

Maddie and David woke up, got dressed and had a quick breakfast. David told Maddie how anxious he felt about his theatre performance tonight. She tried to boost his morale and said to him: “ and enjoy yourself. After all, it is best to concentrate, on demanding theatre parts before you appear on TV. You really have to and go for it".

She even offered to make him his favourite dish, stake and ale pie. David volunteered to help her but she preferred not to have him delicious that its smell and sight So David left and Maddie started coking. When she finished, the food was so Five hours later, Maddie received a very unpleasant phone call. It was a doctor from St. Mary's Hospital who told her 
that her husband had broken his legs. Maddie was so worried and anxious that she had built up a great . David, on the other hand, was so angry that he was for not being able to perform.

When Maddie arrived at the hospital, he saw that her husband was in great pain and asked him to tell her what had happened. David told her that Bill, another actor in the show who despised him, tried to get him to say things he did not believe and fight with the director. David told him that he was annoyed with him because he was trying to . Bill punched him in the face and David not wanting to adopt approach

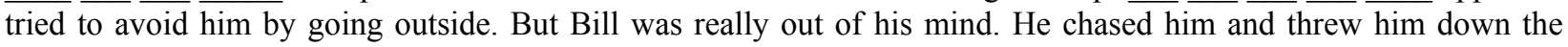
stairs. As if that wasn't enough, he left him until the police found him and untied him.

\section{Notes}

${ }^{1}$ The English idioms, whose meanings were taken from the Collins COBUILD Dictionary of Idioms (2002), were translated into Greek following the Betsis English Idioms in Greek: Collins COBUILD Dictionary (2011), which is a translation of the CCDI into Greek. Since Type A idioms are identical with L1 idioms, no back-translation was provided.

${ }^{2}$ In parentheses, there is a word-for-word back-translation of the equivalent Greek idiomatic expression in Type B, $\mathrm{C} 1, \mathrm{C} 2$ and $\mathrm{D}$ idioms in an effort to provide information about the Greek equivalent. 